\title{
Predictors of work-related sensitisation, allergic rhinitis and asthma in early work life
}

\author{
Jessica Kellberger ${ }^{1}$, Astrid S. Peters-Weist ${ }^{1}$, Sabine Heinrich ${ }^{1}$, Susanne Pfeiffer ${ }^{1}$, \\ Christian Vogelberg ${ }^{2}$, Diana Roller ${ }^{2}$, Jon Genuneit ${ }^{3}$, Gudrun Weinmayr ${ }^{3}$, \\ Erika von Mutius ${ }^{4}$, Christian Heumann ${ }^{5}$, Dennis Nowak ${ }^{1}$ and Katja Radon ${ }^{1}$
}

\begin{abstract}
Affiliations: 'Occupational and Environmental Epidemiology and Net Teaching Unit, Institute and Outpatient Clinic for Occupational, Social and Environmental Medicine, University Hospital of Munich (LMU), Munich, Germany. ${ }^{2}$ Paediatric Dept, University Hospital Carl Gustav Carus Dresden, TU Dresden, Dresden, Germany. ${ }^{3}$ Institute of Epidemiology and Medical Biometry, Ulm University, Ulm, Germany. ${ }^{4} \mathrm{Dr}$. v. Haunersches Kinderspital, University Hospital of Munich (LMU), Munich, Germany. ${ }^{5}$ Dept of Statistics, LMU Munich, Munich, Germany.
\end{abstract}

Correspondence: Jessica Kellberger, Occupational and Environmental Epidemiology and Net Teaching Unit, Institute and Outpatient Clinic for Occupational, Social and Environmental Medicine, University Hospital of Munich (LMU), Ziemssenstr. 1, 80336 Munich, Germany. E-mail: jessica.kellbergeramed.Imu.de

ABSTRACT Although work-related asthma and allergies are a huge burden for society, investigation of occupational exposures in early work life using an unexposed reference group is rare. Thus, the present analyses aimed to assess the potential impact of occupational exposure and other risk factors on the prevalence of work-related sensitisation and incidence of allergic rhinitis/asthma using a population-based approach and taking into account an unexposed reference group.

In SOLAR (Study on Occupational Allergy Risks) II, German participants of ISAAC (International Study of Asthma and Allergies in Childhood) phase II were followed from childhood (9-11 years) until early adulthood (19-24 years). Data on 1570 participants were available to fit predictive models.

Occupational exposure was not statistically significantly associated with disease prevalence/incidence. Sensitisation in childhood, parental asthma, environmental tobacco smoke exposure during puberty, sex and study location were statistically significant predictors of outcome.

Our results indicate that occupational exposure is of little relevance for work-related sensitisation prevalence and allergic rhinitis/asthma incidence in early work life, while other risk factors can be used to improve career guidance for adolescents. Further research on the role of a potential healthy hire effect and the impact of longer exposure duration is needed.

-

@ERSpublications

Occupational exposure not predictive of work-related sensitisation, allergic rhinitis and asthma in early work life http://ow.ly/x5VgM

\footnotetext{
This article has supplementary material available from erj.ersjournals.com

Received: Sept 032013 | Accepted after revision: May 152014 | First published online: June 252014

Support statement: The ISAAC phase II study in Dresden and Munich was funded by the German Ministry of Education and Research (01 EE 9411-3). The SOLAR I study was supported by the German Ministry for Economy and Labour. The SOLAR II study was funded by the German Federal Institute for Occupational Safety and Health and the German Ministry of Labour and Social Affairs.

Conflict of interest: Disclosures can be found alongside the online version of this article at erj.ersjournals.com 


\section{Introduction}

In many countries, occupational asthma is the most common work-related pulmonary disease [1]. It is a chronic disease that may have a differing impact on employees depending on their age or stage of work life [2]. In addition to potential socioeconomic concerns for the affected individual, occupational asthma is associated with a substantial economic burden at the population level $[2,3]$. Depending on the country, the prevalence of asthma seems to vary between $1 \%$ and $18 \%$ [4]; $\sim 16 \%$ of adult asthma is attributable to occupational exposure [5]. The prevalence of work-related rhinitis, which encompasses both occupational rhinitis and work-exacerbated rhinitis, is estimated to be $31-61 \%$. Data on occupational rhinitis itself are scarce [6].

Besides occupational exposure, asthma and allergies are influenced by hereditary and environmental risk factors [7]. Many of these factors have already been reported in infancy, e.g. in birth cohort studies [8]. However, as described by TORÉN et al. [9], substantial investigation of risk factors later in life is rare. Most studies on the incidence of asthma and allergies during the first years of work life were performed in occupational cohorts, e.g. bakery apprentices $[10,11]$. In one of the few population-based studies assessing risk of occupational exposure, the ECRHS (European Community Respiratory Health Survey) [12], an increased risk was seen for asthma [13], but not for allergic rhinitis [14]. For these analyses, only recent or current occupation was taken into account, and data assessment had not necessarily started before work life, thus the incidence of symptoms attributable to occupational exposure was difficult to assess.

Longitudinal analyses of the course of these diseases, especially in the crucial first years of work life, might help to predict new-onset of work-related asthma/allergies. To the best of our knowledge, only one population-based study on occupational asthma/allergies has followed participants from childhood until adulthood, using an unexposed reference group to assess the impact of occupational exposure [15]. However, that study assessed job history retrospectively later in life.

Therefore, the main aim of SOLAR (Study on Occupational Allergy Risks) was to follow participants from ISAAC (International Study of Asthma and Allergies in Childhood) phase II until adulthood in order to collect detailed information on first job experiences and its association with the course of symptoms/ diseases. The objective of this analysis was to assess the potential impact of occupational exposure and other risk factors on participants' respiratory health during the first years of employment.

\section{Methods}

Study population

In 1995-1996, questionnaire and clinical data from 6399 primary school children aged 9-11 years were assessed in the German ISAAC phase II study [16, 17]. The participants were from Munich and Dresden (both Germany) and formed the baseline of this population-based cohort study. Questionnaire data of 3929 participants aged 16-18 years were obtained at first follow-up, SOLAR I, in 2002-2003 [18]. In the second follow-up, SOLAR II (2007-2009) [19], 2051 young adults (19-24 years old) completed a questionnaire and clinical data were assessed for $57 \%$ of them (fig. 1).

The study was approved by the Ethical Committee of the Medical Faculty of the University of Dresden (Dresden, Germany), the Ethical Committee of the Bavarian Chamber of Physicians (Munich) and by the Ethical Committee of the University of Ulm (Ulm, Germany).

Informed consent was obtained from all study participants, or their guardians if the participants were not yet of age $(<18$ years old).

Wherever possible, the questionnaires of the three time-points employed the same validated instruments from the ISAAC and the ECRHS $[12,16]$. Items consisted of sociodemographic, environmental and healthrelated components.

\section{Outcomes and potential predictors}

Sensitisation to the ubiquitous allergens Alternaria tenuis, cat, Dermatophagoides pteronyssinus, Dermatophagoides farinae, mixed grass pollen and mixed tree pollen was tested for in both the ISAAC phase II and SOLAR II studies using skin prick tests (SPT). In addition to these allergens, rye, Ambrosia artemisi ifolia and the following occupational allergens were also tested for in SOLAR II: $\alpha$-amylase, Aspergillus, latex, Lepidoglyphus destructor-Lep d 1, mouse, rat and Tyrophagus. Rye flour was also tested in a subsample of the participants. Response to a single allergen was defined as positive when the corresponding wheal size was $\geqslant 3 \mathrm{~mm}$ larger than the negative control. 


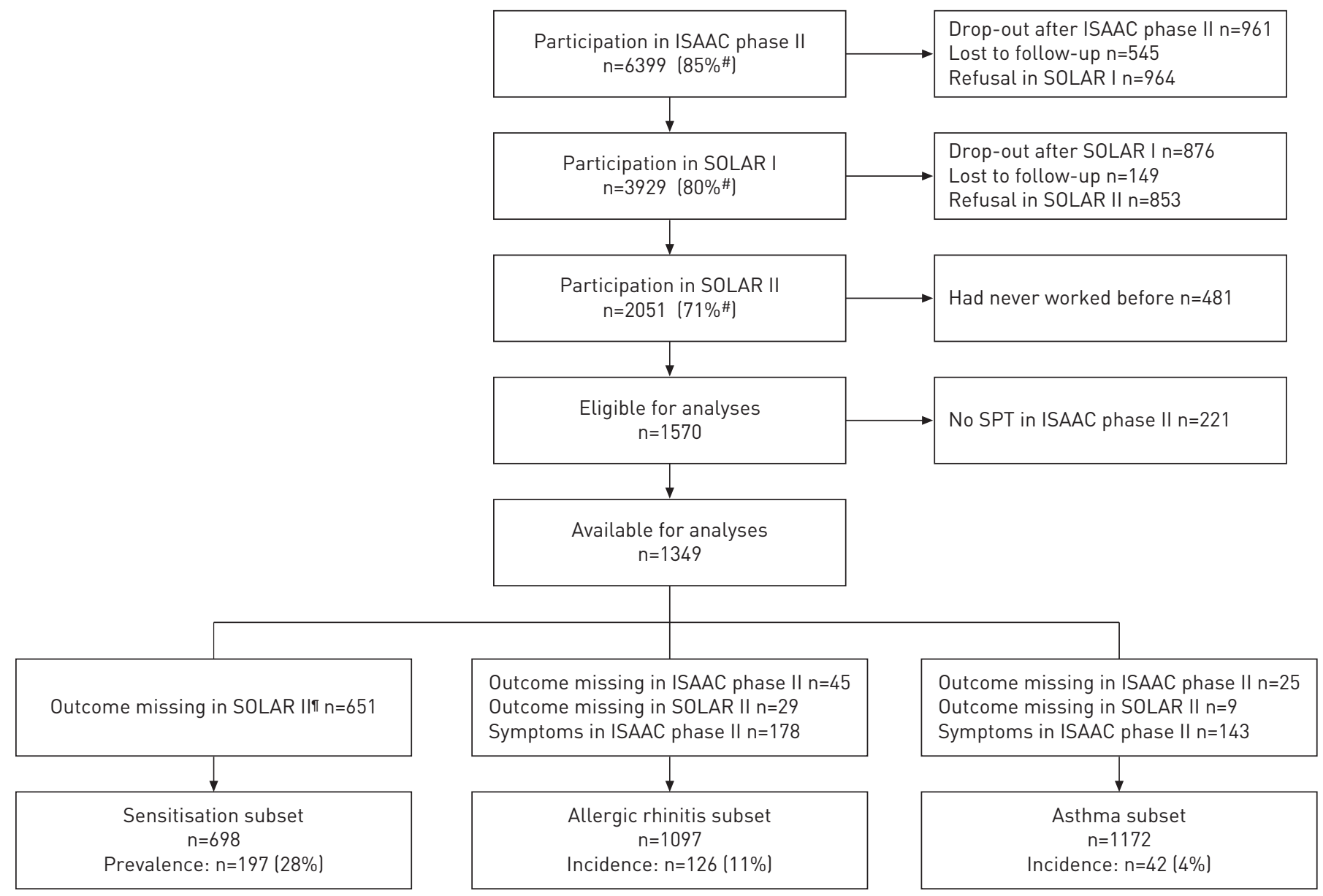

FIGURE 1 Flow chart showing the study participation and formation of the final data analysis subsets. ISAAC: International Study of Asthma and Allergies in Childhood; SOLAR: Study on Occupational Allergy Risks; SPT: skin prick test; drop-out: persons that refused to be contacted again after participation in ISAAC phase II; lost to follow-up: persons that could not be traced or contacted, e.g. due to unknown address, health reasons or death; refusal: persons that could be traced and contacted but refused to participate in the first or second follow-up. "\#: response refers to the net sample after exclusion of drop-outs and those lost to follow-up; ${ }^{\top}$ : SPT missing $(n=584)$ or incomplete $(n=48)$ or use of antihistamine prior to testing $(n=19)$.

\section{Outcomes}

Prevalence of work-related sensitisation in SOLAR II was defined as a positive SPT response to at least one of the occupational allergens described above, except rye flour. Additional analyses for the subset of participants with rye flour SPT are presented in the supplementary material.

Allergic rhinitis was defined as a combination of a physician's diagnosis of allergic rhinitis and a 12-month prevalence of rhinoconjunctivitis symptoms, based on the questionnaire data.

A physician's diagnosis of asthma and either a 12-month prevalence of asthma symptoms or current use of asthma medication, as indicated in the questionnaire, was used to define asthma.

Incidence of allergic rhinitis and asthma was defined as the absence of outcome at baseline but presence of outcome at second follow-up, regardless of the condition at first follow-up. Incident cases were compared to those who did not report outcome at baseline and second follow-up. Hence, for each outcome, only participants who did not report that outcome at baseline were analysed for subsequent incidence. Participants with prevalent symptoms at baseline were excluded from the respective analyses.

\section{Potential predictors}

Participants' complete job histories were assessed by means of the questionnaires in SOLAR I and SOLAR II. These included holiday, part time and permanent jobs as well as internships, apprenticeships and civilian service. Occupational exposure was considered as a potential predictor for incidence of the outcomes described. Thus, only participants who had reported at least one job considered relevant for exposure assessment and data analysis (any job that had been held for $\geqslant 4$ weeks with $\geqslant 8$ working hours per week) were included in the analyses. All the jobs deemed relevant regarding potential exposure were classified 
according to an asthma-specific job exposure matrix [20], and categorised exposure was summarised per participant. Participants' lifetime exposure was defined as presenting either no risk (reference), or low risk or high risk of asthma. If a participant had ever held a relevant job with high risk exposure, their lifetime exposure was set at high risk. If they had not held any high risk job, but at least one with low risk exposure, their lifetime exposure was set at low risk. Only if all the jobs ever held were not associated with any exposure of relevance, was the lifetime exposure set at no risk. Further details are provided in the supplementary material.

Items listed in table 1 were considered as additional potential predictors. Socioeconomic status and sex were considered as confounders and thus adjusted for in all models. SPT response in ISAAC phase II was defined as positive when there was at least one positive response to any of the ubiquitous allergens described above. With the exception of the SPT response, all the information is from the self-reported questionnaire data.

\section{Statistical methods}

Missing information on potential risk factors was assumed to be missing at random. The potential predictors marked in table 1 were multiply imputed, using R software (version 2.10.1; www.R-project.org).

Multiple logistic regression models were fitted for each of the three outcomes, taking all the potential predictors into consideration. The confounders socioeconomic status and sex, as well as occupational exposure, were included in all models. Inclusion of additional predictors was determined in a model selection process based on the Akaike information criterion for each outcome.

Probabilities and odds ratios for prevelance/incidence of the outcomes were calculated for presence of single risk factors and for the full models, including all non-occupational risk factors in combination with either having had: 1) no occupational exposure ever (no risk); or 2) occupational low risk (but no high risk) exposure ever; or 3) occupational high risk exposure ever.

\section{TABLE 1 Potential risk factors considered for fitting the predictive models}

\begin{tabular}{|c|c|c|c|}
\hline Risk factors & Total participants" & Missing data ${ }^{\pi}$ & Imputed \\
\hline Subjects $n$ & 1570 & & \\
\hline Subjects in SOLAR II aged $\leqslant 21$ years $^{+}$ & $552(35.2)$ & 0 & No \\
\hline Female & 918 (58.5) & 0 & No \\
\hline Study location Munich & 758 (48.3) & 0 & No \\
\hline Nationality German & $1518(96.7)$ & $5(0.3)$ & Yes \\
\hline High socioeconomic status ${ }^{\S}$ & $921(58.7)$ & $21(1.3)$ & Yes \\
\hline Exposure to environmental tobacco smoke & & $25(1.6)$ & Yes \\
\hline ISAAC phase II: current exposure & $439(28.0)$ & & \\
\hline ISAAC phase II: former exposure & $135(8.6)$ & & \\
\hline SOLAR I & 960 (61.2) & $6(0.4)$ & Yes \\
\hline Ever smokers ${ }^{f}$ as indicated in SOLAR I & $480(30.6)$ & $12(0.8)$ & Yes \\
\hline Having been breastfed & $1348(85.9)$ & $12(0.8)$ & Yes \\
\hline Kindergarten attendance & 1550 (98.7) & $10(0.6)$ & Yes \\
\hline Presence of siblings & $1273(81.1)$ & $13(0.8)$ & Yes \\
\hline \multicolumn{4}{|l|}{ Parental history of } \\
\hline Allergic rhinitis & 595 (37.9) & $138(8.8)$ & Yes \\
\hline Asthma & $166(10.6)$ & $127(8.1)$ & Yes \\
\hline Atopic dermatitis & $304(19.4)$ & $157(10.0)$ & Yes \\
\hline Positive skin prick test response in ISAAC phase II & $320(23.7)$ & $221(14.1)$ & No \\
\hline Occupational exposure & & $166(10.6)$ & Yes $^{\# \#}$ \\
\hline No risk & $624(39.7)$ & & \\
\hline Low risk & $383(24.4)$ & & \\
\hline High risk & $563(35.9)$ & & \\
\hline
\end{tabular}

Data are presented as $\mathrm{n}(\%)$, unless otherwise stated. SOLAR: Study on Occupational Allergy Risks; ISAAC: International Study of Asthma and Allergies in Childhood. \#: frequencies displayed for one random imputed data set; ": frequencies of missing values before imputation; ${ }^{+}$: age was dichotomised in two groups of comparable range (19-21 years and 22-24 years); ${ }^{\S}$ : mother or father qualified for university entrance or university diploma; ${ }^{f}: \geqslant 1$ pack-year, never-smoker defined as $<1$ pack-year until SOLAR I; \#\# : only missing time values were imputed to assess relevance of job regarding duration and intensity of potential occupational exposure; jobs lasting $\geqslant 4$ weeks with $\geqslant 8$ working hours per week were deemed relevant. 
All analyses were performed with SAS software (version 9.4; SAS Institute, Inc., Cary, NC). Further details are provided in the supplementary material.

\section{Results}

Participants were followed, on average, for 12.2 years between ISAAC phase II and SOLAR II (median (range) 12.2 (10.8-13.8) years). At least one relevant job was indicated by 1570 participants. Of these, 221 with missing baseline SPT values were excluded from the evaluation. Depending on previous symptoms and missing outcome information, data of 698 participants were available for analysis of sensitisation prevalence, 1097 for incidence of allergic rhinitis and 1172 for incidence of asthma (fig. 1).

Unfortunately, it was not possible to include information on kindergarten attendance in the analyses since 99\% of participants had been to kindergarten.

Participants indicated, on average, 2.5 relevant jobs (median (range) 2.0 (1-10)), which they kept for a mean duration of 13 weeks (median (range) 7 (1-91) weeks) per single job. Cumulatively, participants had worked for an average duration of 31 weeks (median (range) 24 (1-242) weeks). 40\% had never had a job with asthma-relevant exposure, while $36 \%$ had worked in at least one job considered to be of high risk.

The four most frequently indicated jobs, as classified by the International Standard Classification of Occupations-88, were office clerks, waiters/waitresses/bartenders, shop sales persons and demonstrators, and institution-based personal care workers.

Prevalence of work-related sensitisation in SOLAR II was $28 \%(n=197)$. The allergens that predominated among the positive SPT results were mouse (19\%), Lep d 1 (18\%) and Tyrophagus (17\%). For allergic rhinitis, $11 \%(n=126)$ of the participants without symptoms or doctor's diagnosis at baseline indicated incident diagnoses with current symptoms, corresponding to an incidence density of nine new cases per 1000 person-years. Reported cumulative incidence for asthma was $4 \%(n=42)$, while the incidence density was three incident cases per 1000 person-years.

\section{Prediction of work-related sensitisation}

Statistically significant predictors for prevalence of work-related sensitisation in SOLAR II were SPT response at baseline, parental history of allergic rhinitis, study location and sex. The overall probability of incidence of work-related sensitisation without occupational exposure was 92\% (95\% CI 77-97\%). The prediction changed only marginally when occupational exposure was included (table 2).

\section{Prediction of allergic rhinitis}

Sex and a positive SPT response in ISAAC phase II were statistically significantly associated with incidence of allergic rhinitis. Moreover, parental history of allergic rhinitis and asthma, and environmental tobacco smoke exposure in SOLAR I improved the model. Occupational exposure did not enhance the prediction quality of the model. The overall probability for incidence of allergic rhinitis without occupational exposure was $63 \%$ (95\% CI 46-78\%). It decreased to 53\% (95\% CI 34-72\%) for the presence of occupational lowrisk exposure (table 3 ).

\section{Prediction of asthma}

In the final model for incident asthma, parental history of asthma, environmental tobacco smoke exposure in SOLAR I and a positive SPT response at baseline showed statistically significant associations. Again, occupational exposure was not statistically significantly associated with the outcome. Altogether, the probability for new-onset of asthma without occupational exposure was 60\% (95\% CI 30-84\%). Including occupational low-risk exposure decreased the probability to $48 \%$ (95\% CI 19-79\%) (table 4).

\section{Discussion}

Due to the early inclusion of participants and the long follow-up time of the study, SOLAR II offers the unique possibility for long-term prediction and exploration of specific predictors for work-related respiratory diseases and allergies in early work life. For the first time, extensive job history and course of health in this age period (i.e. adolescence and early adulthood) could be assessed and analysed in a population-based cohort, including an unexposed reference group.

Among the SOLAR II study participants, $77 \%$ had already had at least one job considered relevant for potential occupational exposure. None of the predictive models showed any statistically significant influence of occupational exposure on the outcomes being investigated. This finding is in accordance with previous studies that did not reveal such an association [21, 22]. However, the results also indicate a "healthy hire effect", with participants not having been exposed to low- or high-risk occupational exposure exhibiting higher risks of presenting with the outcomes than those who were exposed (albeit not statistically 
TABLE 2 Prevalence of work-related sensitisation in SOLAR II from the final multiple regression model

Probability $\%(95 \% \mathrm{Cl})$

7.8

\section{Intercept $\left(\beta_{0}\right)$}

G: general risk factors

Male versus female

Low versus high socioeconomic status

Study location, Munich versus Dresden

Nationality, other versus German

ETS exposure in SOLAR I, no versus yes

Parental history of allergic rhinitis, yes versus no

Positive versus negative SPT response in ISAAC phase II

\section{Occupational exposure}

L: ever versus never having had occupational low-risk exposure

$\mathrm{H}$ : never versus ever having had occupational high risk exposure

\section{Full model, including}

Never had occupational exposure $(\mathrm{G}+\mathrm{H})$

Occupational low-risk exposure ever $(\mathrm{G}+\mathrm{L}+\mathrm{H})$

Occupational high-risk exposure ever $(G)$

Adjusted OR $\left(95 \% \mathrm{Cl}^{\#}\right.$

$\begin{array}{cc}10.8(6.5-17.5) & 1.4(1.0-2.1) \\ 8.6(5.3-13.9) & 1.1(0.7-1.7) \\ 12.7(7.6-20.3) & 1.7(1.1-2.6) \\ 16.4(5.8-38.5) & 2.3(0.8-6.6) \\ 9.7(5.8-15.8) & 1.3(0.9-1.9) \\ 11.1(6.8-17.7) & 1.5(1.0-2.2) \\ 46.9(33.3-61.0) & 10.4(6.9-15.7) \\ 8.0(3.9-15.5) & 1.0(0.6-1.7) \\ 8.4(5.1-13.5) & 1.1(0.7-1.7) \\ & \\ 91.8(77.3-97.3) & 11.2(3.4-36.6) \\ 91.9(77.2-97.5) & 11.4(3.4-38.2) \\ 91.2(75.7-97.2) & 10.3(3.1-34.3)\end{array}$

$\exp \left(\beta_{0}\right)=0.085$. G: general (non-occupational) risk factors; L: occupational low-risk exposure; H: occupational high-risk exposure; ETS: environmental tobacco smoke; SOLAR: Study on Occupational Allergy Risks; SPT: skin prick test; ISAAC: International Study of Asthma and Allergies in Childhood. " : based on the full model $(\mathrm{G}+\mathrm{L}+\mathrm{H}) ;{ }^{\natural}$ : forced in.

significant). It is possible that participants who developed symptoms after ISAAC phase II (but before SOLAR II) intuitively avoided jobs or tasks that would have been associated with certain exposures. Thus, their increased risk for the outcome could have influenced their exposure status, rather than the other way round.

Overall prediction probabilities for prevalent work-related sensitisation were substantially higher than the positive predictive value (PPV) of SPT for new-onset occupational hypersensitivity, which had previously been found in apprentice bakers (33\%) [23]. As seen in previous studies, SPT at baseline was strongly predictive of this outcome [24-26].

Prediction of incidence of allergic rhinitis was moderate, with a maximum overall probability of $63 \%$. The combination of non-occupational predictors included in the model accounts for more than half of the new cases and, thus, is better than SPT alone (PPV 14-49\%) [27, 28]. Intrinsic factors such as parental disease

TABLE 3 Incidence of physician-diagnosed allergic rhinitis up to SOLAR II from the final multiple regression model

\section{Probability \% (95\% Cl)}

Adjusted OR $(95 \% \mathrm{Cl})^{\#}$

\section{Intercept $\left(\beta_{0}\right)$}

\section{G: general risk factors}

Female versus male

High versus low socioeconomic status"

Parental history of allergic rhinitis, yes versus no

Parental history of asthma, yes versus no

ETS exposure in SOLAR I, no versus yes

Positive versus negative SPT response in ISAAC phase II

\section{Occupational exposure}

L: never versus ever having had occupational low-risk exposure

$\mathrm{H}$ : never versus ever having had occupational high risk exposure

\section{Full model, including}

Never had occupational exposure $(\mathrm{G}+\mathrm{L}+\mathrm{H})$

Occupational low-risk exposure ever $(\mathrm{G}+\mathrm{H})$

Occupational high-risk exposure ever $(\mathrm{G}+\mathrm{L})$

\section{7}

$\begin{array}{cc}4.2(2.0-8.5) & 1.6(1.0-2.4) \\ 3.3(1.6-6.8) & 1.2(0.8-1.9) \\ 3.6(1.6-7.7) & 1.3(0.9-2.1) \\ 4.5(1.8-11.0) & 1.7(0.9-3.2) \\ 3.4(1.6-7.4) & 1.3(0.9-1.9) \\ 16.8(8.6-30.0) & 7.2(4.8-11.0) \\ & \\ 4.0(2.3-6.9) & 1.5(0.9-2.6) \\ 2.7(1.5-5.1) & 1.0(0.6-1.6) \\ & \\ 63.4(45.5-78.2) & 1.7(0.8-3.6) \\ 53.5(33.5-72.4) & 1.1(0.5-2.6) \\ 63.2(44.5-78.6) & 1.7(0.8-3.7)\end{array}$

$\exp \left(\beta_{0}\right)=0.028$. G: general (non-occupational) risk factors; L: occupational low-risk exposure; H: occupational high-risk exposure; ETS: environmental tobacco smoke; SOLAR: Study on Occupational Allergy Risks; SPT: skin prick test; ISAAC: International Study of Asthma and Allergies in Childhood. ${ }^{\#}$ : based on the full model $(\mathrm{G}+\mathrm{L}+\mathrm{H}) ;{ }^{\circ}$ : forced in. 
TABLE 4 Incidence of physician-diagnosed asthma up to SOLAR II from the final multiple regression model

Probability \% $(95 \% \mathrm{Cl})$

Adjusted OR $(95 \% \mathrm{CI})^{\#}$

\section{Intercept $\left(\beta_{0}\right)$}

G: general risk factors

Female versus male

Low versus high socioeconomic status"

Parental history of asthma, yes versus no

Parental history of atopic dermatitis, yes versus no

ETS exposure in SOLAR I, yes versus no

Ever versus never smoking status in SOLAR I

Having been breastfed, no versus yes

Positive versus negative SPT response in ISAAC phase II

\section{Occupational exposure}

L: never versus ever having had occupational low-risk exposure

$\mathrm{H}$ : never versus ever having had occupational high risk exposure

\section{Full model, including}

Never had occupational exposure $(\mathrm{G}+\mathrm{L}+\mathrm{H})$

Occupational low-risk exposure ever $(\mathrm{G}+\mathrm{H})$

Occupational high-risk exposure ever $(\mathrm{G}+\mathrm{L})$

0.3

$$
\begin{aligned}
& 0.4(0.1-1.7) \\
& 0.4(0.1-1.6) \\
& 1.0(0.2-4.6) \\
& 0.4(0.1-2.1) \\
& 0.7(0.2-2.5) \\
& 0.5(0.1-2.1) \\
& 0.6(0.1-2.6) \\
& 1.3(0.3-4.9)
\end{aligned}
$$

$0.5(0.2-1.5)$
$0.4(0.1-1.3)$

$60.0(30.0-84.0)$

$48.4(18.5-79.4)$

$54.8(24.8-81.7)$
$1.4(0.7-2.8)$

$1.2(0.6-2.4)$

$3.4(1.5-7.4)$

$1.5(0.7-3.2)$

$2.4(1.0-5.5)$

$1.5(0.8-3.0)$

$1.9(0.8-4.2)$

$4.3(2.2-8.3)$

$1.6(0.7-3.8)$

$1.2(0.6-2.6)$

$1.5(0.4-5.3)$

$0.9(0.2-3.9)$

$1.2(0.3-4.5)$

$\exp \left(\beta_{0}\right)=0.003$. G: general (non-occupational) risk factors; L: occupational low-risk exposure; H: occupational high-risk exposure; ETS: environmental tobacco smoke; SOLAR: Study on Occupational Allergy Risks; SPT: skin prick test; ISAAC: International Study of Asthma and Allergies in Childhood. " : based on the full model $(\mathrm{G}+\mathrm{L}+\mathrm{H})$; ": forced in.

history or SPT seem to be at least as important for allergic rhinitis as modifiable ones. This finding supports European Academy of Allergy and Clinical Immunology recommendations for occupational rhinitis, which stated that no single factors were known that would predict incidence with sufficient certainty (as in high PPV) to exclude persons from jobs associated with probable exposure [29].

The logistic regression model for incidence of asthma had the lowest overall prediction probabilities of all full models with broad confidence intervals, and the single factor probabilities were rather small due to the very low base risk of developing asthma. Including all potential risk factors in the model yielded a high probability of $60 \%$, especially compared to the low PPV of SPT for current asthma (5\%) [28]. The included factors are in accordance with known risk factors for the development of asthma in adulthood [30]. The only modifiable factors were being breastfed and avoidance of environmental tobacco smoke exposure and smoking during puberty.

We could not confirm some of the predictors found in other longitudinal studies on occupational exposure, e.g. parental asthma was not associated with work-related sensitisation in our analyses, and even though sex, socioeconomic status and smoking were included in our asthma prediction model, they were not statistically significant [26, 31-33]. However, those studies were based on occupational cohorts and did not include never-exposed reference groups, so the results are not necessarily comparable.

\section{Strengths and limitations}

Previous studies on the impact of occupational exposure on sensitisation, allergic rhinitis or asthma were mostly based on occupational cohorts only (e.g. apprentice pastry makers, bakery workers and workers exposed to laboratory animals) and, thus, in contrast to our study, did not include an unexposed reference group $[10,11,34]$. However, having such a group is crucial in estimating the excess risk that is attributable to a certain exposure compared to the background risk in the population without that exposure. GHOSH et al. [15] also followed a population-based approach and, thus, were able to include an unexposed reference group. However, complete job history in this study was assessed retrospectively at age 33 years and 42 years. Hence, information, especially from early work life, could be prone to poor recall and, therefore, be less exhaustive and reliable than in the present analyses.

Our results indicate that relevance of occupational exposure in early work life is low compared to other factors that can be easily assessed in childhood. This may initially seem counterintuitive, and may even appear contradictory to the results of some previous studies. However, on closer inspection this is not the case. Some other prospective studies including unexposed reference groups have also indicated that the incidence of asthma and allergies in young adults who had just started their careers was often independent of occupational exposure $[21,22,25]$. 
A limitation of our study might be that even though participants were followed for $\sim 12$ years, they were still very young in SOLAR II and just at the beginning of their working lives. Many studies have shown that incidence of asthma and allergies may be highest in the first 6-12 months of a job [18, 32, 35], whereas our participants had indicated average job durations of 3 months, with a maximum of 21 months. Therefore, exposure times might have been too short to detect potential adverse health effects.

The study population was sampled from the general population; hence it can be assumed that the presented results are essentially representative for the population in Germany. Some response bias was seen in the study, and a few differences were observed comparing those included in the analyses subsets with those excluded because of previous disease or missing values [19] (supplementary material). However, this may bias the results towards the null rather than away from the null. It is unclear whether the associations found in this study also hold true for other populations; further research is needed to assess the generalisability.

Unfortunately, it was not possible to use a time-dependent approach for the analysis of this study, since the exact timing of symptom or disease onset was not known. Information on absence or presence of symptoms was only available for the 12 months prior to each study time point; sensitisation was only assessed at baseline and the second follow-up.

A pre-determined panel of work-related allergens was tested for by SPT regardless of reported jobs and suspected exposures. It is possible that some participants were sensitised to other occupational substances that had not been included in this panel. However, the most relevant work-related allergens for asthma and allergies in Germany were selected for the panel, and it would hardly be possible to test for all existing substances or test specific allergens on an individual basis.

Instead of complete case analysis or single imputation, we used multiple imputation to account for missing values and the uncertainty associated with these. This approach generally assumes that data are missing at random, which unfortunately cannot be tested. However, this procedure has become common practice in epidemiological studies and was shown to perform better than other methods [36].

\section{Conclusion}

In conclusion, we could not show overall a statistically significant contribution of occupational exposures to disease prevalence/incidence; thus, our results might challenge received knowledge. The difference might be explained by a lack of unexposed reference groups in previous studies. More research is needed to assess the role of a potential healthy hire effect and to evaluate longer exposure duration.

\section{Acknowledgements}

We would like to thank the study team and study centres, as well as the scientific advisory council and all participants for their contribution. Martina Unterburger and Martina Feilke (both Occupational and Environmental Epidemiology and Net Teaching Unit, Institute and Outpatient Clinic for Occupational, Social and Environmental Medicine, University Hospital of Munich (LMU), Munich, Germany) are gratefully acknowledged for support in data processing, and Katharina Brinck (Occupational and Environmental Epidemiology and Net Teaching Unit, Institute and Outpatient Clinic for Occupational, Social and Environmental Medicine, University Hospital of Munich (LMU)) for job coding. Moreover, we would like to acknowledge the anonymous reviewers for their constructive feedback and suggestions to improve the quality of the article.

The SOLAR study was strongly influenced by Stephan Weiland (Institute of Epidemiology and Medical Biometry, University of Ulm, Ulm, Germany), and we would like to offer him posthumous thanks for his significant contribution.

\section{References}

Cowl CT. Occupational asthma: review of assessment, treatment, and compensation. Chest 2011; 139: 674-681.

Toren K. Self reported rate of occupational asthma in Sweden 1990-2. Occup Environ Med 1996; 53: 757-761.

Kenyon NJ, Morrissey BM, Schivo M, et al. Occupational asthma. Clin Rev Allergy Immunol 2012; 43: 3-13.

Bateman ED, Hurd SS, Barnes PJ, et al. Global strategy for asthma management and prevention: GINA executive summary. Eur Respir J 2008; 31: 143-178.

Torén K, Blanc PD. Asthma caused by occupational exposures is common - a systematic analysis of estimates of the population-attributable fraction. BMC Pulm Med 2009; 9: 7.

Moscato G, Vandenplas O, Van Wijk RG, et al. EAACI position paper on occupational rhinitis. Respir Res 2009; 10: 16. Muche-Borowski C, Kopp M, Reese I, et al. Allergy prevention. J Dtsch Dermatol Ges 2010; 8: 718-724.

Kjaer HF, Eller E, Andersen KE, et al. The association between early sensitization patterns and subsequent allergic disease. The DARC birth cohort study. Pediatr Allergy Immunol 2009; 20: 726-734.

9 Torén K, Zock JP, Kogevinas M, et al. An international prospective general population-based study of respiratory work disability. Thorax 2009; 64: 339-344.

10 Meijer E, Suarthana E, Rooijackers J, et al. Application of a prediction model for work-related sensitisation in bakery workers. Eur Respir J 2010; 36: 735-742.

11 Walusiak J, Hanke W, Gorski P, et al. Respiratory allergy in apprentice bakers: do occupational allergies follow the allergic march? Allergy 2004; 59: 442-450.

12 Burney P. Ten years of research on asthma in Europe. The European Community Respiratory Health Survey. Rev Epidemiol Sante Publique 1998; 46: 491-496. 
13 Kogevinas M, Zock JP, Jarvis D, et al. Exposure to substances in the workplace and new-onset asthma: an international prospective population-based study (ECRHS-II). Lancet 2007; 370: 336-341.

14 Radon K, Gerhardinger U, Schulze A, et al. Occupation and adult onset of rhinitis in the general population. Occup Environ Med 2008; 65: 38-43.

15 Ghosh RE, Cullinan P, Fishwick D, et al. Asthma and occupation in the 1958 birth cohort. Thorax 2013; 68: $365-371$

16 Asher MI, Keil U, Anderson HR, et al. International Study of Asthma and Allergies in Childhood (ISAAC): rationale and methods. Eur Respir J 1995; 8: 483-491.

17 Weiland SK, von Mutius E, Hirsch T, et al. Prevalence of respiratory and atopic disorders among children in the East and West of Germany five years after unification. Eur Respir J 1999; 14: 862-870.

18 Riu E, Dressel H, Windstetter D, et al. First months of employment and new onset of rhinitis in adolescents. Eur Respir J 2007; 30: 549-555.

19 Heinrich S, Peters A, Kellberger J, et al. Study on Occupational Allergy Risks (SOLAR II) in Germany: design and methods. BMC Public Health 2011; 11: 298.

20 Kennedy SM, Le Moual N, Choudat D, et al. Development of an asthma specific job exposure matrix and its application in the epidemiological study of genetics and environment in asthma (EGEA). Occup Environ Med 2000; 57: 635-641.

21 Cassidy LD, Molenaar DM, Hathaway JA, et al. Trends in pulmonary function and prevalence of asthma in hexamethylene diisocyanate workers during a 19-year period. J Occup Environ Med 2010; 52: 988-994.

22 Elholm G, Omland $\varnothing$, Schlünssen V, et al. The cohort of young Danish farmers - a longitudinal study of the health effects of farming exposure. Clin Epidemiol 2010; 2: 45-50.

23 Walusiak J, Palczynski C, Hanke W, et al. The risk factors of occupational hypersensitivity in apprentice bakers the predictive value of atopy markers. Int Arch Occup Environ Health 2002; 75: Suppl. S117-S121.

24 Archambault S, Malo JL, Infante-Rivard C, et al. Incidence of sensitization, symptoms, and probable occupational rhinoconjunctivitis and asthma in apprentices starting exposure to latex. J Allergy Clin Immun 2001; 107: 921-923.

25 Suarthana E, Malo JL, Heederik D, et al. Which tools best predict the incidence of work-related sensitisation and symptoms. Occup Environ Med 2009; 66: 111-117.

26 Gautrin D, Ghezzo H, Infante-Rivard C, et al. Incidence and determinants of IgE-mediated sensitization in apprentices. A prospective study. Am J Respir Crit Care Med 2000; 162: 1222-1228.

27 Bodtger U, Assing K, Poulsen LK. A prospective, clinical study on asymptomatic sensitisation and development of allergic rhinitis: high negative predictive value of allergological testing. Int Arch Allergy Immunol 2011; 155: 289-296.

28 Tschopp JM, Sistek D, Schindler C, et al. Current allergic asthma and rhinitis: diagnostic efficiency of three commonly used atopic markers (IgE, skin prick tests, and Phadiatop). Results from 8329 randomized adults from the SAPALDIA Study. Swiss Study on Air Pollution and Lung Diseases in Adults. Allergy 1998; 53: 608-613.

29 Moscato G, Vandenplas O, Gerth Van Wijk R, et al. Occupational rhinitis. Allergy 2008; 63: 969-980.

30 Anto JM, Sunyer J, Basagana X, et al. Risk factors of new-onset asthma in adults: a population-based international cohort study. Allergy 2010; 65: 1021-1030.

31 Caldeira RD, Bettiol H, Barbieri MA, et al. Prevalence and risk factors for work related asthma in young adults. Occup Environ Med 2006; 63: 694-699.

32 Skjold T, Dahl R, Juhl B, et al. The incidence of respiratory symptoms and sensitisation in baker apprentices. Eur Respir J 2008; 32: 452-459.

33 Talini D, Monteverdi A, Lastrucci L, et al. One-year longitudinal study of young apprentices exposed to airway occupational sensitizers. Int Arch Occup Environ Health 2006; 79: 237-243.

34 Gautrin D, Ghezzo H, Infante-Rivard C, et al. Long-term outcomes in a prospective cohort of apprentices exposed to high-molecular-weight agents. Am J Respir Crit Care Med 2008; 177: 871-879.

35 Nguyen B, Ghezzo H, Malo JL, et al. Time course of onset of sensitization to common and occupational inhalants in apprentices. J Allergy Clin Immunol 2003; 111: 807-812.

36 van der Heijden GJ, Donders AR, Stijnen T, et al. Imputation of missing values is superior to complete case analysis and the missing-indicator method in multivariable diagnostic research: a clinical example. J Clin Epidemiol 2006; 59: 1102-1109. 